\title{
Flexural strength of heat-polymerized polymethyl methacrylate denture resin reinforced with glass, aramid, or nylon fibers
}

Type:

Article

Abstract:

Statement of problem. Despite the favorable properties of conventional PMMA used as a denture base material, its fracture resistance could be improved. Purpose. This in vitro study was performed to determine whether the flexural strength of a commercially available, heat-polymerized acrylic denture base material could be improved through reinforcement with 3 types of fibers. Material and methods. Ten specimens of similar dimensions were prepared for each of the 4 experimental groups: conventional acrylic resin and the same resin reinforced with glass, aramid, or nylon fibers. Flexural strength was evaluated with a 3-point bending test. The results were analyzed with a 1-way analysis of variance. Results. All reinforced specimens showed better flexural strength than the conventional acrylic resin. Specimens reinforced with glass fibers showed the highest flexural strength, followed by aramid and nylon. Conclusion. Within the limitations of this study, the flexural strength of heat-polymerized PMMA denture resin was improved after reinforcement with glass or aramid fibers. It may be possible to apply these results to distal extension partial denture bases and provisional fixed partial dentures.

\begin{tabular}{|c|l|}
\hline Author & $\begin{array}{l}\bullet \text { John, J. } \\
\bullet \text { Gangadhar, S. A. } \\
\end{array}$ \\
& $\begin{array}{l}\bullet \text { Shah, I. } \\
\text { Source }\end{array}$ \\
\hline ISSN & Journal of Prosthetic Dentistry \\
\hline DOI & $1022-3913$ \\
\hline Volume (Issue) & $86(4)$ \\
\hline Page & $424-427$ \\
\hline Year & 2001 \\
\hline
\end{tabular}

Keyword:

linear polyethylene fibers, mechanical-properties, impact strength resistance, fracture, metal 
Please Cite As:

JOHN, J., GANGADHAR, S. A. \& SHAH, I. 2001. Flexural strength of heatpolymerized polymethyl methacrylate denture resin reinforced with glass, aramid, or nylon fibers. Journal of Prosthetic Dentistry, 86, 424-427.

URL:

- http://apps.webofknowledge.com search via Accession No >> WOS:000172075200015

- http://www.scopus.com/inward/record.url?eid=2-s2.00035487436\&partnerlD=40\&md5=e1f88c98cee09a0c3455fa9b90da3cae

- http://www.ncbi.nlm.nih.gov/pubmed/11677538

- http://www.sciencedirect.com/science/article/pii/S0022391301431258 